\title{
The evaluation of $\beta$-adrenoceptor blocking agents in patients with COPD and congestive heart failure: a nationwide study
}

\author{
This article was published in the following Dove Press journal: \\ International Journal of COPD \\ 26 August 2017 \\ Number of times this article has been viewed
}

\author{
Kuang-Ming Liao ${ }^{1, *}$ \\ Tien-Yu Lin ${ }^{2,3}$ \\ Yaw-Bin Huang ${ }^{2,3}$ \\ Chen-Chun $\mathrm{Kuo}^{2, *}$ \\ Chung-Yu Chen ${ }^{2,3}$ \\ 'Department of Internal Medicine, \\ Chi Mei Medical Center, Chiali, Tainan, \\ ${ }^{2} \mathrm{School}$ of Pharmacy, Kaohsiung \\ Medical University, ${ }^{3}$ Department \\ of Pharmacy, Kaohsiung Medical \\ University Hospital, Kaohsiung, \\ Taiwan, Republic of China \\ *These authors contributed equally \\ to this work
}

\begin{abstract}
Objective: $\beta$-Blockers are safe and improve survival in patients with both congestive heart failure (CHF) and COPD. However, the superiority of different types of $\beta$-blockers is still unclear among patients with $\mathrm{CHF}$ and COPD. The association between $\beta$-blockers and CHF exacerbation as well as COPD exacerbation remains unclear. The objective of this study was to compare the outcome of different $\beta$-blockers in patients with concurrent CHF and COPD.
\end{abstract}

Patients and methods: We used the National Health Insurance Research Database in Taiwan to conduct a retrospective cohort study. The inclusion criteria for CHF were patients who were $>20$ years old and were diagnosed with CHF between January 1, 2005 and December 31, 2012. COPD patients included those who had outpatient visit claims $\geq 2$ times within 365 days or 1 claim for hospitalization with a COPD diagnosis. A time-dependent Cox proportional hazards regression model was applied to evaluate the effectiveness of $\beta$-blockers in the study population.

Results: We identified 1,872 patients with concurrent CHF and COPD. Only high-dose bisoprolol significantly reduced the risk of death and slightly decreased the hospitalization rate due to CHF exacerbation (death: adjusted hazard ratio $[\mathrm{aHR}]=0.51,95 \%$ confidence interval $[C I]=0.29-0.89$; hospitalization rate due to $\mathrm{CHF}$ exacerbation: $\mathrm{aHR}=0.48,95 \% \mathrm{CI}=0.23-1.00$ ). No association was observed between $\beta$-blocker use and COPD exacerbation.

Conclusion: In patients with concurrent $\mathrm{CHF}$ and $\mathrm{COPD}, \beta$-blockers reduced mortality, $\mathrm{CHF}$ exacerbation, and the need for hospitalization. Bisoprolol was found to reduce mortality and CHF exacerbation compared to carvedilol and metoprolol.

Keywords: congestive heart failure, COPD, $\beta$-blockers, acute exacerbation

\section{Introduction}

Although the survival rate has improved over time, mortality remains high in patients with congestive heart failure (CHF). ${ }^{1} \mathrm{COPD}$ is a common disease among patients with $\mathrm{CHF}$, and according to a previous study, the prevalence is $\sim 30 \%{ }^{2}$ COPD patients have a high prevalence of cardiovascular disease, including $\mathrm{CHF},{ }^{3-9}$ because the two diseases share common risk factors and pathogenic mechanisms, such as smoking and systemic inflammation. Previous observational studies have demonstrated that $\beta$-blockers could improve survival in patients with concurrent CHF and COPD. ${ }^{10}$ Moreover, studies have shown that selective and nonselective $\beta$-blockers have different effects on airways due to their selectivity. ${ }^{2}$ Metoprolol, bisoprolol, and nebivolol are candidate drugs for patients with COPD and CHF. ${ }^{10}$ One study enrolled 63 elderly patients with mild to moderate $\mathrm{CHF}$ and moderate to severe COPD to compare the effects of bisoprolol and carvedilol treatment, ${ }^{11}$ and they found that bisoprolol improved
Correspondence: Chung-Yu Chen School of Pharmacy, Kaohsiung Medical University, 100, Shih-Chuan Ist Road, Kaohsiung 80708, Taiwan, Republic of China

Tel +886 73I2 II 01 ext 2375

Email jk2975525@hotmail.com 
pulmonary function and caused fewer adverse events than carvedilol. In a recent study, $\mathrm{Su}$ et $\mathrm{al}^{12}$ found that in patients with concurrent CHF and COPD, bisoprolol but not carvedilol or metoprolol could provide a dose-response survival benefit. Patients with CHF and COPD are prescribed many medications, including angiotensin-converting-enzyme inhibitors (ACEIs), angiotensin receptor blockers (ARBs), mineralocorticoid receptor antagonists, statins, hydralazine, and isosorbide dinitrate, and these medications may affect their prognosis. However, in the study by $\mathrm{Su}$ et al, ${ }^{12}$ these medications were not further controlled or adjusted. Thus, the aim of our study was to investigate the effectiveness of different $\beta$-blockers in patients with $\mathrm{CHF}$ and COPD after adjusting for these cardiovascular medications.

\section{Patients and methods}

Taiwan launched a single-payer National Health Insurance Program on March 1, 1995, and $>99.9 \%$ of Taiwan's population was enrolled. We used the Longitudinal Health Insurance Database 2005 (LHID2005) to conduct our study. The LHID2005 contains all original claim data of the $1,000,000$ beneficiaries enrolled in 2005 who were randomly sampled from $\sim 25.68$ million individuals in this registry. The LHID2005 constitutes all registration and claim data of these 1,000,000 individuals collected by the National Health Insurance Program. No significant difference was observed in the sex distribution between the patients in the LHID2005 and the original National Health Insurance Research Database (NHIRD). This study was approved by the Institutional Review Board of the Kaohsiung Medical University Hospital (KMUHIRB-EXEMPT (II) 20170006), and the database accessed has deidentified data. The current NHIRD, hospital regulations and guidelines did not indicate a need for informed consent in this retrospective cohort study due to de-identified secondary data. All procedures were in accordance with the ethical standards of the Institutional Research Committee and the directives of the Declaration of Helsinki.

\section{Study design and population CHF criteria}

The inclusion criteria for CHF were patients $>20$ years old with a diagnosis of CHF (ICD-9: 401.91, 402.11, 404.01, 404.03, 404.11, 404.91, 404.93, and 428) between January 1, 2005 and December 31, 2012. Patients with CHF were also required to have $\geq 3$ outpatient visit claims with CHF diagnoses within 365 days or 1 claim for hospitalization with a CHF diagnosis. ${ }^{13,14}$ The exclusion criteria consisted of the following: 1) a length of hospital stay longer than
180 days; 2 ) no use of CHF-related drugs ( $\beta$-blockers, ACEIs, $\mathrm{ARBs}$, aliskiren, diuretics, milrinone, hydralazine, isosorbide dinitrate, and isosorbide mononitrate) within 1 year after the index date; and 3) death within 30 days after heart failure (HF) diagnosis.

\section{COPD criteria}

COPD patients included those with a diagnosis of ICD-9 codes 490-492 and 496 between January 1, 2005 and December 31, 2012 (the date of concurrent HF and COPD diagnoses was defined as the index date). COPD patients were also required to have $\geq 2$ outpatient visit claims within 365 days or 1 claim for hospitalization with a COPD diagnosis. ${ }^{15-17}$ The exclusion criterion was death within 30 days after the first date of concurrent HF and COPD diagnoses.

\section{Study group}

$\beta$-Blocker nonusers were defined as patients who used any $\beta$-blocker $<90$ days after the index date. $\beta$-Blocker users were defined as patients who used any $\beta$-blocker $>90$ days after the index date. The study subjects were further assigned to groups according to the average daily dose of $\beta$-blockers in each 90-day period, which was treated as a time-dependent covariate. Patients were classified into three categories according to their medication dose. The group of nonusers was further divided into carvedilol $<3.125 \mathrm{mg} /$ day, bisoprolol $<0.625 \mathrm{mg} /$ day, and metoprolol $<25 \mathrm{mg}$ /day subgroups. The low-dose groups consisted of the carvedilol $\geq 3.125$ and $<6.25 \mathrm{mg} /$ day, bisoprolol $\geq 0.625$ and $<1.25 \mathrm{mg} /$ day, and metoprolol $\geq 25$ and $<50 \mathrm{mg} /$ day subgroups. The high-dose groups included the carvedilol $\geq 6.25 \mathrm{mg} /$ day, bisoprolol $\geq 1.25 \mathrm{mg} /$ day, and metoprolol $\geq 50 \mathrm{mg} /$ day subgroups. Baseline characteristics included age, sex, number of HF and COPD exacerbation patients in the past year, HF and COPD exacerbation rate in the past year, comorbidities, and co-medications. Comorbidities were identified if two diagnoses were coded for an outpatient visit or if one diagnosis was coded during an inpatient visit 1 year before the index date. Co-medications were identified if they were used longer than 30 days.

\section{Outcomes}

The primary end point was death, and the secondary end points were hospitalization due to $\mathrm{CHF}$ exacerbation and hospitalization due to COPD exacerbation. Study subjects were followed until the abovementioned events occurred or until the end of data collection. In addition, a lag time of 90 days was applied to the $\beta$-user group. The censor date was adjusted to evaluate the long-term effects of $\beta$-blockers. 


\section{Propensity-score matching}

We used 1:1 propensity-score matching to balance the baseline characteristics between $\beta$-blocker users and $\beta$-blocker nonusers. Baseline characteristics, including age, sex, comorbidities, and co-medication, were used to generate the predicted probability by logistic regression. The subsequent analyses were implemented in matched cohorts.

\section{Statistical analysis}

Differences in baseline characteristics were evaluated using a chi-square test (categorical variables) or Student's $t$-test (continuous variables) in age, number of HF exacerbation patients in the past year, number of COPD exacerbation patients in the past year. A time-dependent Cox proportional hazards regression model was used to evaluate the effects of $\beta$-blockers on survival outcome and hospitalization rates due to CHF exacerbation and COPD exacerbation, using the $\beta$-blocker group as the time-dependent covariate. The model was adjusted by age, sex, number of HF and COPD exacerbation patients in the past year, HF and COPD exacerbation rate in the past year, comorbidities, and co-medication. The age, comorbidities, and co-medications adjusted in the model were time-varying. All analyses were performed using the SAS statistical software (version 9.4; SAS Institute Inc., Cary, NC, USA), and a $P$-value $<0.05$ was considered statistically significant.

\section{Results}

A total of 17,956 patients diagnosed with CHF between 2005 and 2012 were included. After excluding patients with a hospital stay longer than 180 days $(n=425)$, who did not use any CHF-related medications ( $\mathrm{n}=2,335)$, or who died within 30 days after CHF diagnosis ( $\mathrm{n}=322), 14,875$ CHF patients were included in this study. Regarding the patients with concurrent $\mathrm{CHF}$ and COPD, 1,838 patients were diagnosed with COPD during the study period. A total of 1,820 patients were finally included after excluding 18 subjects who died within 30 days after the index date.

\section{Patients with CHF and COPD}

A total of $589 \beta$-blocker users (200 carvedilol, 331 bisoprolol, 10 metoprolol, and 48 combinations) and 1,231 $\beta$-blocker nonusers were included. Their baseline characteristics are shown in Table 1. In the full cohort, the age of $\beta$-blocker nonusers was significantly higher than that of $\beta$-blocker users $(P<0.001)$. Among comorbidities, the incidence rates of dyslipidemia, ischemic heart disease, myocardial infarction, cerebrovascular disease, and malignancy were significantly different between $\beta$-blocker users and nonusers. In addition, the use of ACEIs/ARBs, calcium channel blockers, statins, other lipid-lowering agents, systemic $\beta 2$-agonists, shortacting $\beta$-agonists, short-acting muscarinic antagonists, xanthine, and oral corticosteroid was also significantly different between the two groups.

After propensity-score matching, 577 patients were included in each of the $\beta$-blocker user (including 194 carvedilol, 326 bisoprolol, 10 metoprolol, and 47 combinations) and nonuser groups (Figure 1). Except for the higher proportion of patients using statins in $\beta$-blocker user group, age, sex, number of HF and COPD exacerbation patients in the past year, HF and COPD exacerbation rate in the past year, comorbidities, and co-medications were similar between the two groups.

\section{Comparison of $\beta$-blocker users and $\beta$-blocker nonusers}

Table 2 shows the association between $\beta$-blocker use and primary or secondary end points after propensity-score matching. $\beta$-Blocker users had a significantly lower risk of death from any cause (adjusted hazard ratio [aHR] $=0.67$, $95 \%$ confidence interval $[\mathrm{CI}]=0.47-0.96, P=0.028)$ and hospitalization due to $\mathrm{HF}$ ( $\mathrm{aHR}=0.62,95 \% \mathrm{CI}=0.39-0.98$, $P=0.042$ ). However, the hospitalization rate for COPD was not significantly different between $\beta$-blocker users and nonusers $(\mathrm{aHR}=1.15,95 \% \mathrm{CI}=0.73-1.83, P=0.549)$.

Regarding individual $\beta$-blockers after propensity-score matching (Tables 3 and 4), most did not significantly reduce the risk of death from any cause or the hospitalization rate due to HF, except for high-dose bisoprolol (death from any cause: aHR $=0.51,95 \% \mathrm{CI}=0.29-0.89, P=0.017$; hospitalization rate due to HF: aHR $=0.47,95 \% \mathrm{CI}=0.23-1.00$, $P=0.050$ ). However, none of the $\beta$-blockers were associated with a reduced risk of hospitalization for COPD.

\section{Discussion}

High-dose bisoprolol may reduce the risk of death in patients with CHF and COPD In a study by Guder et al, ${ }^{2} \beta$-blockers were well-tolerated in patients with COPD, and $\beta 1$-selective $\beta$-blockers were recommended for any patient with COPD and CHF. However, the study population, type of $\beta$-blockers, inclusion criteria, and study outcomes were different among studies. ${ }^{18-28}$ The information regarding carvedilol, bisoprolol, and metoprolol use was limited in patients with CHF and COPD. In our study, we found that any-cause death and the hospitalization rates due to CHF were lower in patients with CHF and COPD who were receiving $\beta$-blocker therapy than in those not receiving $\beta$-blocker therapy, but no significant difference in acute 
Table I Baseline characteristics of $\beta$-blocker users and nonusers among heart failure patients with COPD

\begin{tabular}{|c|c|c|c|c|c|c|}
\hline \multirow[t]{3}{*}{ Characteristics } & \multicolumn{3}{|c|}{ Full cohort } & \multicolumn{3}{|c|}{ Matched cohort } \\
\hline & \multirow{2}{*}{$\begin{array}{l}\beta \text {-Blocker } \\
\text { users } \\
\mathrm{n}=589\end{array}$} & \multirow{2}{*}{$\begin{array}{l}\beta \text {-Blocker } \\
\text { nonusers }\end{array}$} & \multirow[t]{2}{*}{$P$-value } & \multirow{2}{*}{$\begin{array}{l}\beta \text {-Blocker } \\
\text { users } \\
n=577\end{array}$} & \multirow{2}{*}{$\begin{array}{l}\beta \text {-Blocker } \\
\text { nonusers } \\
n=577\end{array}$} & \multirow[t]{2}{*}{$P$-value } \\
\hline & & & & & & \\
\hline Age (years), mean (SD) & $70.7(12.5)$ & $75.2(12.0)$ & $<0.00 I^{*}$ & $7 \mid .4(12.4)$ & $7 I .1(12.2)$ & 0.694 \\
\hline Sex: males, n (\%) & $342(58.1)$ & $703(57.1)$ & 0.699 & $335(58.1)$ & $333(57.7)$ & 0.905 \\
\hline Number of $\mathrm{HF}$ exacerbation patients in the past year, $\mathrm{n}(\%)$ & $30(5.1)$ & $75(6.1)$ & 0.452 & $29(5.0)$ & $29(5.0)$ & 1.000 \\
\hline HF exacerbation rate, mean (SD) & $0.11(0.4)$ & $0.14(0.6)$ & 0.399 & $0.11(0.4)$ & $0.14(0.8)$ & 0.448 \\
\hline Number of COPD exacerbation patients in the past year, $n(\%)$ & $18(3.1)$ & $62(5.0)$ & 0.066 & $18(3.1)$ & $22(3.8)$ & 0.630 \\
\hline COPD exacerbation rate, mean (SD) & $0.06(0.4)$ & $0.10(0.4)$ & 0.083 & $0.06(0.4)$ & $0.08(0.4)$ & 0.488 \\
\hline \multicolumn{7}{|l|}{ Comorbidities, $n(\%)$} \\
\hline Hypertension & $425(72.2)$ & $849(69.0)$ & 0.165 & $4 \mid 5(7 \mid .9)$ & $4 I I(7 \mid .2)$ & 0.794 \\
\hline DM & $189(32.1)$ & $378(30.7)$ & 0.552 & $182(31.5)$ & $185(32.1)$ & 0.850 \\
\hline Dyslipidemia & $159(27.0)$ & $205(16.7)$ & $<0.00 I^{*}$ & $150(26)$ & $135(23.4)$ & 0.306 \\
\hline IHD & $277(47.0)$ & $447(36.3)$ & $<0.00 I^{*}$ & $266(46.1)$ & $265(45.9)$ & 0.963 \\
\hline MI & $45(7.6)$ & $65(5.3)$ & $0.048 *$ & $4 I(7 . I I)$ & $34(5.9)$ & 0.403 \\
\hline $\mathrm{AF}$ & 70 (II.9) & $133(10.8)$ & 0.493 & $68(11.8)$ & $48(8.3)$ & 0.050 \\
\hline Arrhythmia & $133(22.6)$ & $271(22.0)$ & 0.786 & $128(22.2)$ & $119(20.6)$ & 0.518 \\
\hline Atherosclerosis & II (I.9) & $27(2.2)$ & 0.649 & II (I.9) & $8(1.4)$ & 0.588 \\
\hline PVD & $21(3.6)$ & $35(2.8)$ & 0.404 & $21(3.6)$ & $14(2.4)$ & 0.230 \\
\hline CKD & $51(8.7)$ & $97(7.9)$ & 0.570 & $48(8.3)$ & $50(8.7)$ & 0.833 \\
\hline Cerebrovascular disease & $121(20.5)$ & $356(28.9)$ & $<0.00 I^{*}$ & $120(20.8)$ & $113(19.6)$ & 0.608 \\
\hline Liver cirrhosis & $58(9.9)$ & $92(7.5)$ & 0.085 & $56(9.7)$ & $58(10.1)$ & 0.844 \\
\hline Malignancy & $29(4.9)$ & $93(7.6)$ & $0.036 *$ & $28(4.9)$ & $42(7.3)$ & 0.084 \\
\hline Depression & $24(4.1)$ & $43(3.5)$ & 0.538 & $24(4.2)$ & $19(3.3)$ & 0.437 \\
\hline Ulcer & $|3|(22.2)$ & $269(21.9)$ & 0.851 & $127(22.0)$ & $118(20.5)$ & 0.517 \\
\hline \multicolumn{7}{|l|}{ Co-medications, n (\%) } \\
\hline ACEI/ARB & $325(55.2)$ & $599(48.7)$ & $0.009 *$ & $314(54.4)$ & $289(50.1)$ & 0.141 \\
\hline $\mathrm{CCB}$ & 347 (58.9) & $637(51.8)$ & $0.004^{*}$ & $336(58.2)$ & $342(59.3)$ & 0.720 \\
\hline Digoxin & $57(9.7)$ & $146(\mid 1.9)$ & 0.166 & $56(9.7)$ & $57(9.9)$ & 0.921 \\
\hline Diuretics & $304(51.6)$ & $682(55.4)$ & 0.129 & $297(51.5)$ & $306(53.0)$ & 0.596 \\
\hline Hydralazine & $15(2.6)$ & $21(1.7)$ & 0.228 & $15(2.6)$ & $9(1.6)$ & 0.216 \\
\hline Isosorbide & $125(2 \mid .2)$ & $259(21.0)$ & 0.929 & $|2|(2 \mid .0)$ & $118(20.5)$ & 0.828 \\
\hline Other lipid-lowering agents & $50(8.5)$ & $60(4.9)$ & $0.003 *$ & $45(7.8)$ & $39(6.8)$ & 0.497 \\
\hline Statins & $133(22.6)$ & $170(13.8)$ & $<0.00 I^{*}$ & $126(21.8)$ & $98(17.0)$ & $0.037^{*}$ \\
\hline Warfarin & $24(4.1)$ & $36(2.9)$ & 0.199 & $24(4.2)$ & $16(2.8)$ & 0.198 \\
\hline Antiplatelet drugs & $254(43.1)$ & $480(39.0)$ & 0.093 & $247(42.8)$ & $229(39.7)$ & 0.282 \\
\hline Systemic $\beta 2$ agonists & $91(15.5)$ & $261(21.2)$ & $0.004 *$ & $89(15.4)$ & $104(18.0)$ & 0.237 \\
\hline SABA & $51(8.66)$ & $210(17.1)$ & $<0.00 I^{*}$ & $51(8.8)$ & $55(9.5)$ & 0.684 \\
\hline LABA & $0(0.0)$ & $\mathrm{I}(0.1)$ & 1.000 & $0(0)$ & $0(0)$ & - \\
\hline SAMA & $31(5.3)$ & $176(14.3)$ & $<0.00 I^{*}$ & $31(5.4)$ & $30(5.2)$ & 0.895 \\
\hline LAMA & $9(1.5)$ & $21(1.7)$ & 0.780 & $9(1.6)$ & II (I.9) & 0.652 \\
\hline ICS & $36(6.1)$ & $73(5.9)$ & 0.878 & $35(6.1)$ & $31(5.4)$ & 0.612 \\
\hline ICS + LABA & $25(4.2)$ & $50(4.1)$ & 0.854 & $24(4.2)$ & $19(3.3)$ & 0.437 \\
\hline Xanthine & $145(24.6)$ & $383(3 \mathrm{I} .1)$ & $0.004 *$ & $144(25.0)$ & $167(28.9)$ & 0.127 \\
\hline Oral corticosteroids & $87(14.8)$ & $296(24.1)$ & $<0.001$ & $85(14.7)$ & $110(19.1)$ & 0.059 \\
\hline PPI, $\mathrm{H}_{2}$-antagonists & $125(2 \mid .2)$ & $311(25.3)$ & 0.059 & $|2|(2 \mid .0)$ & $132(22.9)$ & 0.434 \\
\hline OAD agents & $146(24.8)$ & $290(23.6)$ & 0.565 & $|4|(24.4)$ & $143(24.8)$ & 0.891 \\
\hline Insulin & $52(8.8)$ & $118(9.6)$ & 0.604 & $50(8.7)$ & $44(7.6)$ & 0.519 \\
\hline NSAIDs & $221(37.5)$ & $449(36.5)$ & 0.665 & $218(37.8)$ & $224(38.8)$ & 0.716 \\
\hline
\end{tabular}

Note: *Statistically significant $(P<0.05)$.

Abbreviations: $A C E I / A R B$, angiotensin-converting-enzyme inhibitor/angiotensin II receptor blocker; $A F$, atrial fibrillation; $C C B$, calcium channel blocker; $C K D$, chronic kidney disease; DM, diabetes mellitus; ICS, inhaled corticosteroids; IHD, ischemic heart disease; LABA, long-acting $\beta$-agonist; LAMA, long-acting muscarinic antagonist; OAD, oral anti-diabetes; PPI, proton-pump inhibitor; PVD, peripheral vascular disease; MI, myocardial infarction; NSAIDs, nonsteroidal anti-inflammatory drugs; SABA, shortacting $\beta$-agonist; SAMA, short-acting muscarinic antagonist.

exacerbation of COPD was observed between users and nonusers. In additional analyses, only high-dose bisoprolol showed a significant difference in reducing any-cause death in patients with CHF and COPD.

Van Gestel et al evaluated consecutive COPD patients who were undergoing major vascular surgery. The results demonstrated that cardioselective $\beta$-blocker use was associated with lower mortality (hazard ratio $[\mathrm{HR}]=0.67$, $95 \% \mathrm{CI}=0.47-0.96$ ) during a median follow-up of 5 years. ${ }^{25}$ Another study including 2,230 COPD patients showed that $\beta$-blockers could lower all-cause mortality. Similar to our study, only cardioselective $\beta$-blockers demonstrated a 


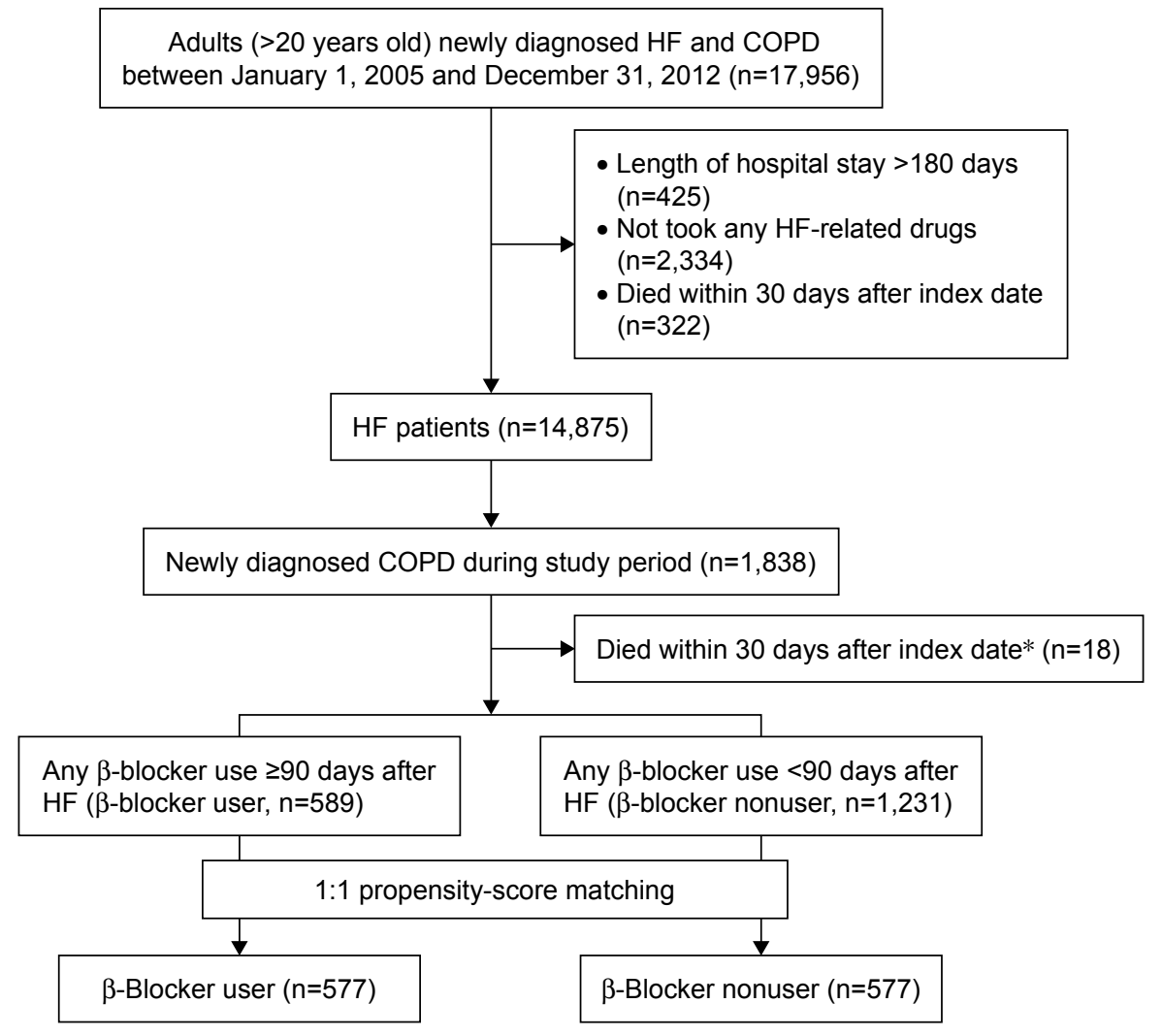

Figure I Study flow chart and results of study population selection.

Note: *Index date in patients with HF and COPD was defined as the date coexisting HF and COPD.

Abbreviation: HF, heart failure.

significant reduction in mortality. ${ }^{27}$ In contrast, one study demonstrated that the HR for 60-day mortality and the odds ratios for 60- and 90-day mortality or rehospitalization were not significantly different between cardioselective and nonselective $\beta$-blockers. Long-term effects were not assessed in this study. ${ }^{29}$

A retrospective study conducted by Su et a ${ }^{12}$ using the NHIRD evaluated the effects of use of different $\beta$-blockers in patients with CHF and COPD. In their study, only bisoprolol was associated with survival benefits in patients with CHF and COPD. Some differences were present between our study and their study. We identified COPD patients as those with diagnoses of ICD-9 codes 490-492 and 496 according to the guidelines for the management of COPD in Taiwan. ${ }^{30,31}$ $\mathrm{Su}$ et $\mathrm{l}^{12}$ included patients diagnosed with bronchiectasis (ICD-9 code: 494), which is not considered COPD. The inclusion of patients with bronchiectasis may explain why their study included more subjects than our study. ${ }^{32,33}$ In our study, the inclusion criteria were at least three outpatient visits or one hospitalization in the CHF population and at least two outpatient visits or one hospitalization in the COPD population, whereas the previous study did not specify details

Table 2 Primary and secondary end points for $\beta$-blocker users and $\beta$-blocker nonusers among heart failure patients with COPD

\begin{tabular}{|c|c|c|c|c|c|c|}
\hline Outcome & Events & Person-years & cHR $(95 \% \mathrm{Cl})$ & $P$-value & aHR $(95 \% \mathrm{Cl})$ & $P$-value \\
\hline \multicolumn{7}{|l|}{ Death from any cause } \\
\hline Nonuser (reference) & 220 & $3,676.19$ & - & - & - & - \\
\hline User & 40 & $\mathrm{I}, 266.4 \mathrm{I}$ & $0.52(0.37-0.73)$ & $<0.00 I^{*}$ & $0.67(0.47-0.96)$ & $0.028^{*}$ \\
\hline \multicolumn{7}{|c|}{ Hospitalization due to HF exacerbation } \\
\hline Nonuser (reference) & 121 & $3,354.4 I$ & - & - & - & - \\
\hline User & 23 & $\mathrm{I}, \mathrm{I} 54.7 \mathrm{I}$ & $0.53(0.34-0.83)$ & $0.006 *$ & $0.62(0.39-0.98)$ & $0.042^{*}$ \\
\hline \multicolumn{7}{|c|}{ Hospitalization due to COPD exacerbation } \\
\hline Nonuser (reference) & 84 & $3,411.12$ & - & - & - & - \\
\hline User & 26 & $1,228.93$ & $0.82(0.53-1.28)$ & 0.381 & $1.15(0.73-1.83)$ & 0.549 \\
\hline
\end{tabular}

Note: *Statistically significant $(P<0.05)$.

Abbreviations: aHR, adjusted hazard ratio; $\mathrm{CHR}$, crude hazard ratio; $\mathrm{Cl}$, confidence interval; $\mathrm{HF}$, heart failure. 
Table 3 Death from any cause among patients using different $\beta$-blockers in the $\beta$-blocker user and $\beta$-blocker nonuser groups of heart failure patients with COPD

\begin{tabular}{|c|c|c|c|c|c|c|}
\hline \multirow[t]{2}{*}{ Group } & \multicolumn{6}{|c|}{ Death from any cause } \\
\hline & Events & Person-years & cHR (95\% CI) & $P$-value & aHR (95\% CI) & $P$-value \\
\hline Nonuser (reference) & 220 & $3,676.19$ & - & - & - & - \\
\hline Carvedilol, low dose & II & 150.66 & $1.22(0.67-2.23)$ & 0.523 & $\mathrm{I} .43(0.77-2.67)$ & 0.261 \\
\hline Carvedilol, high dose & 7 & 298.6 & $0.39(0.18-0.82)$ & $0.014^{*}$ & $0.51(0.24-1.10)$ & 0.086 \\
\hline Bisoprolol, low dose & 8 & 172.6 & $0.79(0.39-1.59)$ & 0.501 & $0.82(0.40-1.67)$ & 0.578 \\
\hline Bisoprolol, high dose & 14 & 611.51 & $0.37(0.22-0.64)$ & $<0.00 I^{*}$ & 0.51 (0.29-0.89) & $0.017^{*}$ \\
\hline Metoprolol, low dose & 0 & 11.59 & - & - & - & - \\
\hline Metoprolol, high dose & 0 & 9.37 & - & - & - & - \\
\hline Combination & 0 & 12.08 & - & - & - & - \\
\hline
\end{tabular}

Note: *Statistically significant $(P<0.05)$.

Abbreviations: aHR, adjusted hazard ratio; $\mathrm{cHR}$, crude hazard ratio; $\mathrm{Cl}$, confidence interval.

regarding selection criteria. ${ }^{13-17}$ Due to these differences, the low-dose range subgroups in the $\beta$-blocker group in our study may be different from the population included in the other study. Otherwise, cardiovascular and respiratory medications played a critical role in determining the prognosis of patients with CHF and COPD. However, these data did not include baseline characteristics and did not adjust for these factors in the statistical analyses. In summary, we conducted a more comprehensive study to evaluate the effectiveness of $\beta$-blockers in CHF patients with COPD and adjusted for the confounding factors of medication, including cardiovascular and respiratory medications.

\section{$\beta$-Blockers and CHF exacerbation in patients with $\mathrm{CHF}$ and COPD}

In the study of Su et al, ${ }^{12}$ only the survival differences between different types of $\beta$-blockers were determined. We not only used time-varying covariates in the survival analyses but also surveyed the incidence of hospitalization due to exacerbated CHF and COPD. To the best of our knowledge, this is the first study to evaluate CHF exacerbation in patients with CHF and COPD using different types of $\beta$-blockers. Similar to the results of any-cause death, only high-dose bisoprolol significantly reduced the risk of CHF rehospitalization ( $\mathrm{aHR}=0.48,95 \% \mathrm{CI}=0.23-1.00, P=0.05)$ in patients with $\mathrm{CHF}$ and COPD. A prospective study to examine the effects of different types of $\beta$-blockers on CHF exacerbation in patients with CHF and COPD may be warranted. Cardioselective $\beta$-blockers are considered a better choice due to the better airway function observed after administration. ${ }^{10}$ A Cochrane Library meta-analysis concluded that cardioselective $\beta$-blockers did not produce a change in the forced expiratory volume in 1 second $\left(\mathrm{FEV}_{1}\right)$ after a single dose or treatment for a longer duration ( 2 days to 16 weeks). ${ }^{34}$ However, these studies were limited by small sample sizes, short follow-up periods, and a lack of CHF patients.
Additionally, nonselective $\beta$-blockers were thought to cause detrimental effects on the respiratory system due to $\beta 2$-receptor blockade. In addition to propranolol, which significantly decreased the $\mathrm{FEV}_{1}, \beta$-blockers induced dyspnea and other related adverse effects in many studies. Few studies have evaluated carvedilol use in patients with CHF. ${ }^{10}$ A triple crossover trial included 35 patients with $\mathrm{CHF}$ and COPD. The $\mathrm{FEV}_{1}$ was lowest with carvedilol treatment $(1.85 \mathrm{~L})$, intermediate with metoprolol treatment $(1.94 \mathrm{~L})$, and highest with bisoprolol treatment $(2.0 \mathrm{~L}){ }^{35}$ The study showed that cardioselective $\beta$-blocker use was associated with better lung function, but this finding could not be conclusively determined due to limitations of sample size, study design, and a short follow-up period. $\beta$-Blockers could induce bronchoconstriction, but their effect on long-term disease severity or COPD exacerbation requires further study.

\section{$\beta$-Blockers and hospitalization due to COPD exacerbation}

In our study, no association was found between different types of $\beta$-blockers and the hospitalization rate due to COPD exacerbation. A meta-analysis demonstrated that treatment with $\beta$-blockers was associated with a significantly reduced risk of hospitalization due to COPD exacerbation (relative risk $=0.63 ; 95 \% \mathrm{CI}=50.57-0.71),{ }^{36}$ but this study had a high degree of heterogeneity and some limitations. The study enrolled COPD patients with different types of cardiovascular diseases, such as hypertension, myocardial infarction, vascular disease, and acute coronary syndrome as well as patients who had undergone coronary artery bypass grafting. The dose of $\beta$-blockers administered was not well-defined, and the study end point was not COPD exacerbation.

A previous randomized study compared effects of bisoprolol and carvedilol in patients with coexisting COPD and CHF and found that bisoprolol improved pulmonary 


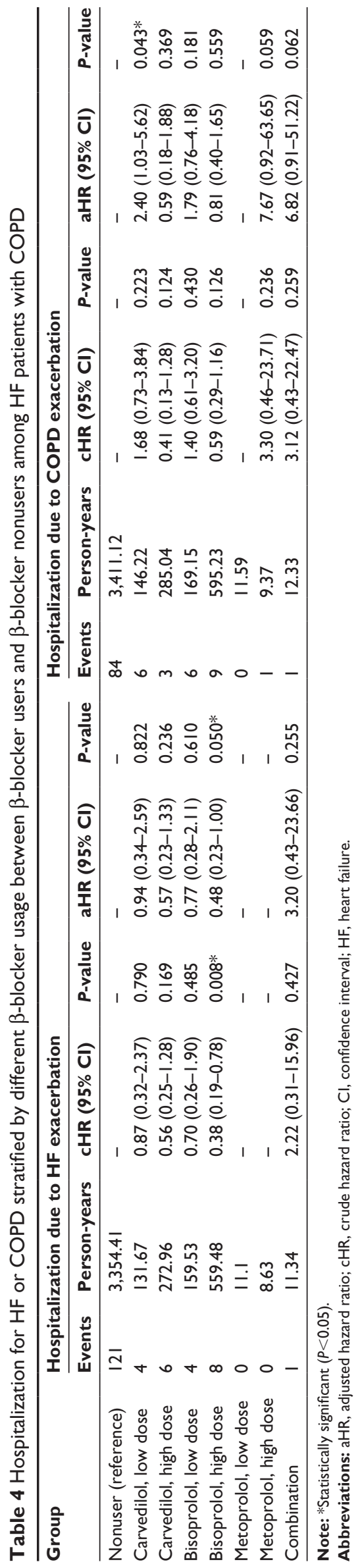

function and caused less pulmonary adverse events than carvedilol. ${ }^{11}$

Bisoprolol had a tendency to decrease heart rate during exercise to a slightly greater extent than carvedilol although there is no statistically significant difference. At rest, increasing doses of bisoprolol decreased heart rates but increasing doses of carvedilol increased heart rate. Bisoprolol is a potent $\beta$-blocker both at rest and during exercise. These clinical consequences of carvedilol may be caused by a reflex increase in sympathetic drive due to a decrease in blood pressure resulting from the $\alpha$-blocking effects of the drug. ${ }^{37}$

In the present study, we recruited patients with CHF and COPD, used time-dependent covariates to eliminate bias that may have resulted from drug exposure over time, and focused on COPD exacerbation. Despite the evidence of $\beta$-blocker effectiveness in CHF and well-tolerance in COPD, clinicians are reluctant to use them in patients concomitant with CHF and COPD due to a perceived contraindication and fear of inducing adverse reactions and bronchoconstriction. It is possible that lack of $\beta$-blocker use despite an obvious indication in CHF patients may indicate either suboptimal care from physicians or poor compliance from patients. If either is true, it is unsurprising that worse outcomes are present in the untreated group.

\section{Strength and limitations}

Marciniak et $\mathrm{al}^{38}$ published retrospective data from the Cooperative Cardiovascular Project in 1998 that found lower 1 -year mortality in subjects prescribed $\beta$-blockers, but this effect was lost in subjects with severe COPD or who were on $\beta$-agonists. Salpeter et $\mathrm{al}^{34}$ found that cardioselective $\beta$-blockers were not associated with adverse events in mild to moderate COPD, despite small declines in $\mathrm{FEV}_{1}$. These studies were considered during formulation of the current guidelines recommending $\beta$-blockers for all CHF patients with COPD.$^{39} \mathrm{Su}$ et al ${ }^{12}$ found that in patients with concurrent CHF and COPD, bisoprolol but not carvedilol or metoprolol could provide a dose-response survival benefit. However, cardiovascular medications were not further controlled or adjusted, and our study investigated the effectiveness of different $\beta$-blockers in patients with CHF and COPD after adjusting for these cardiovascular medications.

Our study used a large health insurance database to evaluate the effectiveness of $\beta$-blockers in patients with CHF and COPD. Additionally, applying the time-dependent model to compute drug exposure may help to more appropriately determine the relationship between medication use and the risk of end points. Although clinical studies have shown the efficacy of $\beta$-blockers in patients with CHF and COPD, 
this study compared the effects of different $\beta$-blockers on mortality, CHF exacerbation, and COPD exacerbation.

However, there were some limitations in our study. First, because the data were obtained from a database, patient demographic information, such as body mass index, smoking status, alcohol use, laboratory data, blood pressure, heart rate, and heart function (ejection fraction, diastolic function, and signs or symptoms of CHF), was not available. Second, although we used a counting process to calculate drug exposure, the adherence of patients to medical treatment was unknown.

\section{Conclusion}

Bisoprolol was associated with reduced mortality and $\mathrm{CHF}$ exacerbation in patients with $\mathrm{CHF}$ and COPD. In concurrent CHF and COPD patients, $\beta$-blockers did not attenuate the risk of COPD exacerbation.

\section{Acknowledgments}

This work was supported by grants from the Kaohsiung Medical University Hospital (KMUH105-M512).

\section{Disclosure}

The authors report no conflicts of interests in this work.

\section{References}

1. Go AS, Mozaffarian D, Roger VL, et al; American Heart Association Statistics Committee and Stroke Statistics Subcommittee. Heart disease and stroke statistics - 2014 update: a report from the American Heart Association. Circulation. 2014;129(3):e28-e292.

2. Güder G, Brenner S, Störk S, Hoes A, Rutten FH. Chronic obstructive pulmonary disease in heart failure: accurate diagnosis and treatment. Eur J Heart Fail. 2014;16(12):1273-1282.

3. Liao KM, Liang FW, Li CY. Risks of all-cause and site-specific fractures among hospitalized patients with COPD. Medicine (Baltimore). 2016;95(40):e5070.

4. Liao KM, Lu HY. Complications after total knee replacement in patients with chronic obstructive pulmonary disease: a nationwide case-control study. Medicine (Baltimore). 2016;95(37):e4835.

5. Chen CY, Liao KM. Chronic obstructive pulmonary disease is associated with risk of chronic kidney disease: a nationwide case-cohort study. Sci Rep. 2016;6:25855.

6. Liao KM, Lu HY. A National analysis of complications following total hip replacement in patients with chronic obstructive pulmonary disease. Medicine (Baltimore). 2016;95(12): 3182.

7. Ho CH, Chen YC, Chu CC, Wang JJ, Liao KM. Postoperative complications after coronary artery bypass grafting in patients with chronic obstructive pulmonary disease. Medicine (Baltimore). 2016;95(8): e2926.

8. Chen CY, Liao KM. The incidence of deep vein thrombosis in Asian patients with chronic obstructive pulmonary disease. Medicine (Baltimore). 2015;94(44):e1741.

9. Liao KM, Ho CH, Ko SC, Li CY. Increased risk of dementia in patients with chronic obstructive pulmonary disease. Medicine (Baltimore). 2015;94(23):e930.

10. Hawkins NM, Petrie MC, Macdonald MR, et al. Heart failure and chronic obstructive pulmonary disease the quandary of beta-blockers and beta-agonists. J Am Coll Cardiol. 2011;57(21):2127-2138.
11. Lainscak M, Podbregar M, Kovacic D, Rozman J, von Haehling S. Differences between bisoprolol and carvedilol in patients with chronic heart failure and chronic obstructive pulmonary disease: a randomized trial. Respir Med. 2011;105(suppl 1):S44-S49.

12. Su VY, Chang YS, Hu YW, et al. Carvedilol, bisoprolol, and metoprolol use in patients with coexistent heart failure and chronic obstructive pulmonary disease. Medicine (Baltimore). 2016;95(5):e2427.

13. Tang CH, Wang CC, Chen TH, Hong CY, Sue YM. Prognostic benefits of carvedilol, bisoprolol, and metoprolol controlled release/extended release in hemodialysis patients with heart failure: a 10-year cohort. $J$ Am Heart Assoc. 2016;5(1):e002584.

14. Tang $\mathrm{CH}$, Chen $\mathrm{TH}$, Wang CC, Hong CY, Huang KC, Sue YM. Renin-angiotensin system blockade in heart failure patients on long-term haemodialysis in Taiwan. Eur J Heart Fail. 2013;15(10): 1194-1202.

15. Li CH, Chen WC, Liao WC, et al. The association between chronic obstructive pulmonary disease and Parkinson's disease: a nationwide population-based retrospective cohort study. QJM. 2015;108(1): $39-45$.

16. Tsai MJ, Chen CY, Huang YB, et al. Long-acting inhaled bronchodilator and risk of vascular events in patients with chronic obstructive pulmonary disease in Taiwan population. Medicine (Baltimore). 2016; 95(8):e78fe.

17. Chung WS, Lai CY, Lin CL, Kao CH. Adverse respiratory events associated with hypnotics use in patients of chronic obstructive pulmonary disease: a population-based case-control study. Medicine (Baltimore). 2015;94(27):e1110.

18. Gottlieb SS, McCarter RJ, Vogel RA. Effect of beta-blockade on mortality among high-risk and low-risk patients after myocardial infarction. N Engl J Med. 1998;339(8):489-497.

19. Chen J, Radford MJ, Wang Y, Marciniak TA, Krumholz HM. Effectiveness of beta-blocker therapy after acute myocardial infarction in elderly patients with chronic obstructive pulmonary disease or asthma. $J \mathrm{Am}$ Coll Cardiol. 2001;37(7):1950-1956.

20. Sin DD, McAlister FA. The effects of beta-blockers on morbidity and mortality in a population-based cohort of 11,942 elderly patients with heart failure. Am J Med. 2002;113(8):650-656.

21. Au DH, Bryson CL, Fan VS, et al. Beta-blockers as single-agent therapy for hypertension and the risk of mortality among patients with chronic obstructive pulmonary disease. Am J Med. 2004;117(12):925-931.

22. Staszewsky L, Wong M, Masson S, et al; Valsartan Heart Failure Trial Investigators. Clinical, neurohormonal, and inflammatory markers and overall prognostic role of chronic obstructive pulmonary disease in patients with heart failure: data from the Val-HeFT heart failure trial. J Card Fail. 2007;13(10):797-804.

23. Malerba M, Montuschi P, Radaeli A, Pirisi M. Role of beta-blockers in patients with COPD: current perspective. Drug Discov Today. 2015; 20(1):129-135.

24. Dransfield MT, Rowe SM, Johnson JE, Bailey WC, Gerald LB. Use of beta blockers and the risk of death in hospitalised patients with acute exacerbations of COPD. Thorax. 2008;63(4):301-305.

25. van Gestel YR, Hoeks SE, Sin DD, et al. Impact of cardioselective betablockers on mortality in patients with chronic obstructive pulmonary disease and atherosclerosis. Am J Respir Crit Care Med. 2008;178(7): 695-700.

26. Hawkins NM, Huang Z, Pieper KS, et al; Valsartan in Acute Myocardial Infarction Trial Investigators. Chronic obstructive pulmonary disease is an independent predictor of death but not atherosclerotic events in patients with myocardial infarction: analysis of the valsartan in acute myocardial infarction trial (VALIANT). Eur J Heart Fail. 2009;11(3): 292-298.

27. Rutten FH, Zuithoff NP, Hak E, Grobbee DE, Hoes AW. Beta-blockers may reduce mortality and risk of exacerbations in patients with chronic obstructive pulmonary disease. Arch Intern Med. 2010;170(10): 880-887.

28. Short PM, Lipworth SI, Elder DH, Schembri S, Lipworth BJ. Effect of beta blockers in treatment of chronic obstructive pulmonary disease: a retrospective cohort study. BMJ. 2011;342:d2549. 
29. Mentz RJ, Wojdyla D, Fiuzat M, Chiswell K, Fonarow GC, O'Connor CM. Association of beta-blocker use and selectivity with outcomes in patients with heart failure and chronic obstructive pulmonary disease (from OPTIMIZE-HF). Am J Cardiol. 2013;111(4): $582-587$.

30. Guideline for the Management of Chronic Obstructive Pulmonary Disease. Taiwan Society of Pulmonary and Critical Care Medicine; 2007. Available from: http://tmuh.tmu.edu.tw/tmuh_web/Chest/pdf/ Chest_teaching_k.pdf. Accessed June 23, 2016.

31. Guideline for the Management of Chronic Obstructive Pulmonary Disease. Taiwan Society of Pulmonary and Critical Care Medicine; 2017. Available from: http://www.rtsroc.org.tw/branch/archive/news/item/ $2 / 2017 \%$ E5\%B $\%$ B $4 \%$ E5\%8F\%B0\%E7\%81\%A3COPD $\% 20 \%$ E $\%$ A $8 \%$ BA $\%$ E7\%99\%82\%E6\%8C $\% 87 \%$ E5\%BC $\% 95-1 . p d f$. Accessed June 23, 2017.

32. Hung CT, Li SF, Lee MH, et al. Trends and burden of bronchiectasisassociated hospitalizations in Taiwan, 1998-2008. J Med Health. 2013; 2(2):43-52.

33. Seitz AE, Olivier KN, Steiner CA, Montes de Oca R, Holland SM, Prevots DR. Trends and burden of bronchiectasis-associated hospitalizations in the United States, 1993-2006. Chest. 2010;138(4): 944-999.
34. Salpeter S, Ormiston T, Salpeter E. Cardioselective beta-blockers for chronic obstructive pulmonary disease. Cochrane Database Syst Rev. 2005;4:CD003566.

35. Jabbour A, Macdonald PS, Keogh AM, et al. Differences between betablockers in patients with chronic heart failure and chronic obstructive pulmonary disease: a randomized crossover trial. J Am Coll Cardiol. 2010;55(17):1780-1787.

36. Du Q, Sun Y, Ding N, Lu L, Chen Y. Beta-blockers reduced the risk of mortality and exacerbation in patients with COPD: a meta-analysis of observational studies. PLoS One. 2014;9(11):e113048.

37. Koshucharova G, Klein W, Lercher P, et al. Different beta-blocking effects of carvedilol and bisoprolol in humans. J Clin Basic Cardiol. 2001; 4(1):53-56.

38. Marciniak TA, Ellerbeck EF, Radford MJ, et al. Improving the quality of care for medicare patients with acute myocardial infarction: results from the cooperative cardiovascular project. JAMA. 1998; 279(17):1351-1357.

39. Heart Failure Society of America, Lindenfeld J, Albert NM, et al. HFSA 2010 comprehensive heart failure practice guideline. J Card Fail. 2010;16(6):e1-e194.
International Journal of COPD

\section{Publish your work in this journal}

The International Journal of COPD is an international, peer-reviewed journal of therapeutics and pharmacology focusing on concise rapid reporting of clinical studies and reviews in COPD. Special focus is given to the pathophysiological processes underlying the disease, intervention programs, patient focused education, and self management protocols.

\section{Dovepress}

This journal is indexed on PubMed Central, MedLine and CAS. The manuscript management system is completely online and includes a very quick and fair peer-review system, which is all easy to use. Visit http://www.dovepress.com/testimonials.php to read real quotes from published authors. 